\title{
Contraceptive Methods and Informed Consent among Women Receiving Medications with Potential for Adverse Fetal Effects: A Washington, Wyoming, Alaska, Montana, Idaho (WWAMI) Region Study
}

\author{
Rex W. Force, PharmD, Gina A. Keppel, MPH, Janelle Guirguis-Blake, MD, \\ Debra A. Gould, MD, MPH, Chris Vincent, MD, Kavitha Chunchu, MD, \\ Robert M. Monger, MD, FACP, John T. Holmes, PharmD, Jacintha Cauffield, PharmD, \\ and Laura-Mae Baldwin, MD, MPH
}

Background: Increasing diabetes, hypertension, and hypercholesterolemia rates expose some young women to medications with potential adverse fetal effects, such as angiotensin-converting enzyme inhibitors (ACE-Is), angiotensin receptor blockers (ARBs), and statins. This study examined whether quality improvement $(\mathrm{QI})$ interventions promote informed consent and contraception to minimize risks with use of ACE-I/ARB/statins.

Methods: This longitudinal cohort study at 7 clinics abstracted medical records of 328 women aged 18 to 44 with $\geq 1$ prescription for ACE-I/ARB/statins and $\geq 1$ visit for hypertension, diabetes, or hypercholesterolemia during the previous year. We measured informed consent documentation and contraceptive methods before and after $Q I$ interventions in which providers contacted their patients to discuss medication risks and benefits.

Results: Of 179 women who were not surgically sterilized, only $11.7 \%$ had documented informed consent related to the risks of ACE-I/ARB/statin use. One hundred fifty-eight women were eligible for the QI intervention (not surgically sterilized, no documented informed consent); only 76 (48.1\%) received the intervention. Before the intervention, $23.7 \%$ of these 76 were "at risk" of an adverse fetal effect. After the intervention, only $7.9 \%(P \leq .001)$ were "at risk" because some women started contraception, discontinued ACE-I/ARB/statins, or changed drug class.

Conclusions: Women prescribed ACE-I/ARB/statins were not consistently using contraception or were not consistently informed of the risks. Provider-implemented QI interventions improved care but were difficult to accomplish, suggesting that new interventions are needed. (J Am Board Fam Med 2012;25:661-668.)

Keywords: Contraception, Drugs, Informed Consent, Pharmacology, Physician Behavior, Practice-based Research, Practice-based Research Networks, Preconception Care, Teratogens

Rates of hypertension, hypercholesterolemia, and diabetes are increasing in the United States, especially among younger populations, largely related

This article was externally peer reviewed.

Submitted 1 March 2012; revised 12 June 2012; accepted 19 June 2012.

From the Departments of Family Medicine and Pharmacy Practice, Idaho State University, Pocatello (RWF, JTH); the Department of Family Medicine, University of Washington, Seattle (GAK, L-MB); the Tacoma Family Medicine Residency Program, Tacoma, WA (JG-B); the Central Washington Family Medicine Residency Program, Yakima, WA (DAG); the Swedish Family Medicine Residency-First Hill, Seattle, WA (CV); The Everett Clinic, Everett, WA (KC); to the obesity epidemic. ${ }^{1-3}$ For example, the number of adults diagnosed with diabetes tripled from 5.6 million in 1980 to 19.7 million in $2009 .{ }^{4}$ Pro-

the University of Wyoming Family Medicine Residency Program at Cheyenne, Cheyenne, WY (RMM); the Lloyd L. Gregory School of Pharmacy, Palm Beach Atlantic University, West Palm Beach, FL (JC).

Funding: This research was supported by the National Center for Research Resources and the National Center for Advancing Translational Sciences, National Institutes of Health, through grant no. 3UL1RR025014.

Prior presentation: This project was presented at the 2010 North American Primary Care Research Group Annual Meeting, Seattle, Washington. 
fessional organizations have developed recommendations and guidelines for the treatment of these conditions, ${ }^{2,5,6}$ and, concomitantly, there has been an associated increase in patients treated for hypertension and hypercholesterolemia. ${ }^{1,3,7}$ The percent of hypertensive patients treated with medications has increased significantly, from $60.3 \%$ in 1999 to 2002 to $69.9 \%$ in 2005 to $2008 .^{8}$ Likewise, statin use has increased significantly, from $19.6 \%$ of adults with high low-density lipoprotein cholesterol levels in 1999 to 2000 to $35.9 \%$ of their counterparts in 2003 to $2004 .^{3}$ Treating fertile women who have these conditions exposes them to potentially serious adverse fetal effects from medications such as angiotensin-converting enzyme inhibitors (ACE-Is), angiotensin receptor blockers (ARBs), and 3-hydroxy-3-methylglutaryl-coenzyme A reductase inhibitors (statins).

ACE-I and ARB drug classes are labeled with US Food and Drug Administration-mandated pregnancy warnings and are classified as pregnancy category $\mathrm{D}$ in the second and third trimesters. Although previously believed safe for use during the first trimester, early fetal exposure to ACE-Is has been associated with major cardiovascular malformations, fetal hypotension and renal dysfunction, hypocalvaria, and other central nervous system malformations. ${ }^{9} 10$ Fewer data are available for ARBs, though there are reports of adverse fetal effects similar to those of ACE-Is. ${ }^{10}$ Because of premarketing animal studies indicating significant fetal harm, statins are US Food and Drug Administration pregnancy category X. ${ }^{1-13}$ Despite these warnings, recent reports indicate women of childbearing age increasingly use these medications. ${ }^{14,15}$

Several studies documenting high prescription rates of medications with potential adverse fetal effects among women of childbearing age also have documented incomplete reproductive counseling or prescription of contraception. ${ }^{16,17}$ However, these studies may not be generalizable to community-based primary care settings in the United States because they (1) were conducted in Veterans Affairs ${ }^{16}$ or health maintenance organization set-

Conflict of interest: none declared.

Disclaimer: The content is solely the responsibility of the authors and does not necessarily represent the official views of the National Institutes of Health.

Corresponding author: Laura-Mae Baldwin, MD, MPH, Department of Family Medicine, University of Washington, Box 354982, Seattle, WA 98195 (E-mail: lmb@uw.edu). tings ${ }^{17}$ or outside the United States ${ }^{6}$; (2) were retrospective claims analyses ${ }^{14}$; (3) were based on physicians' self-reported prescribing practices ${ }^{18} ;$ (4) were based in a single site ${ }^{19}$; or (5) did not specifically address ACE-I, ARB, ${ }^{17,20}$ or statin ${ }^{6,14}$ medications.

This study extends the work of these investigators by examining use of these medications and contraception among women of childbearing age in a network of primary care clinics in the Pacific Northwest, and by examining whether these women were informed of their medication risks. The study also sought to determine whether clinics' existing quality improvement (QI) mechanisms could promote discussion between providers and their patients about the potential risks of ACE-Is, ARBs, or statins and implement medication or contraceptive changes, when appropriate, to decrease these risks.

\section{Methods \\ Study Design}

This was a longitudinal cohort study with data abstraction from patient medical records before and 2 months after QI interventions were implemented at each clinical site.

\section{Setting}

The study was conducted at 7 family medicine clinics in the Washington, Wyoming, Alaska, Montana, Idaho region Practice and Research Network (WPRN). Participating clinics, all based in family medicine residency training programs, averaged 31,729 outpatient visits per year (range, 18,061-55,779). The WPRN Coordinating Center, based at the University of Washington's Department of Family Medicine, coordinated the study. The study received approval from the University of Washington Human Subjects Division as well as each of the participating sites' institutional review boards or through Federalwide Assurance for sites without their own institutional review board.

\section{Study Population}

The study population comprised premenopausal adult women of childbearing age (18-44 years) with a diagnosis of hypertension, hypercholesterolemia, or diabetes who visited the clinic within 12 months of the initial data abstraction date. Inclu- 
sion also required an active prescription for an ACE-I, ARB, or statin within the same 12-month period. Pregnant women were excluded.

\section{Study Procedures}

Each site followed a protocol designed by a collaborative group of WPRN Coordinating Center faculty, staff, and study site colleagues. Queries of the electronic medical record (EMR) or the billing database identified the study sample. The Coordinating Center staff trained the site lead and medical record abstractors in performing the chart abstraction on the basis of a detailed manual customized to each site. Five sites had EMRs; 2 sites had paper charts at the time of the data abstraction. At baseline (before QI intervention), abstractors gathered medical records data from multiple fields and sources: demographics, social history, medical history, surgical history, sexual history, laboratory results, the problem list, the medication list, the diagnosis list, the list of clinical encounters, and chart notes from annual medical and gynecologic examination visits up to 2 years before the abstraction date. Using data from this chart abstraction, the site lead notified clinic providers of any patients eligible for the QI intervention. These were women who were taking an ACE-I, ARB, or statin and who had no documentation of surgical sterilization (defined as tubal ligation or hysterectomy in this study) and no documentation of informed consent about the potential adverse fetal effects of these medications. The Coordinating Center protocol included as eligible those women reporting abstinence and female-only sexual partners because they may choose to become pregnant at any time. Approximately 2 months after the QI intervention was initiated, abstractors gathered data from interactions (eg, telephone encounters, visits) that the patients had had with the clinic since the QI intervention. Chart abstraction data were de-identified and transferred to the Coordinating Center for analysis. Chart information obtained before and after the QI intervention is listed in Table 1.

\section{QI Process}

Each study site implemented a QI intervention after completing the first abstraction. The Coordinating Center provided educational materials that could be used to inform study site providers about the potential adverse fetal effects of ACE-Is, ARBs, and statins and recommended intervention procedures and content. Each site used these materials to design a QI intervention that fit local circumstances. A common QI intervention component across the sites included contacting individual patients who were taking an ACE-I, ARB, or statin and who had no documentation of surgical sterilization to discuss the benefits and risks of the target medications and to decide whether to make changes in these medications or in the patient's contraceptive method. The Coordinating Center materials recommended that the sites contact patients within 1 week of identifying them as eligible for the QI intervention. Telephone calls were the main vehicle for contacting patients. Two clinics used certified letters to ensure that all patients were reached. The site leaders asked providers to docu-

Table 1. Chart Information Obtained before and after the Quality Improvement Intervention

\begin{tabular}{lc}
\hline Before Intervention & After Intervention ( $\geq 2$ Months Later) \\
$\begin{array}{l}\text { Documentation of informed consent about medication (ACE-I, } \\
\text { ARB, or statin) risks }\end{array}$ & $\begin{array}{c}\text { Documentation of informed consent about medication } \\
\text { (ACE-I, ARB, or statin) risks } \\
\text { Active prescription for ACE-I, ARB, or statin medications } \\
\text { Active prescription for ACE-I, ARB, or statin medications }\end{array}$ \\
$\begin{array}{l}\text { Contraceptive methods (surgical and nonsurgical) } \\
\text { Menopausal status }\end{array}$ & $\begin{array}{c}\text { Documentation of quality improvement intervention in } \\
\text { the time since the first abstraction }\end{array}$ \\
$\begin{array}{l}\text { Diagnosis of hypertension, diabetes, or hypercholesterolemia } \\
\text { Documentation of changes in contraceptive methods, } \\
\text { medications (ACE-I, ARB, or statin), or both }\end{array}$ \\
$\begin{array}{c}\text { Patient demographics, including age, insurance, and marital status } \\
\text { Number of visits and number of providers seen at the clinic }\end{array}$ \\
$\begin{array}{l}\text { Puring the past } 12 \text { months } \\
\text { practitioner) }\end{array}$
\end{tabular}

ACE-I, angiotensin-converting enzyme inhibitor; ARB, angiotensin receptor blocker. 
ment the follow-up and outcome in each patient's medical record.

\section{Outcome Measures}

The study outcomes included evidence of informed consent about the adverse fetal effects of the target medications, as well as use and types of contraception. We defined contraceptive methods as surgical sterilization (hysterectomy or tubal ligation); partner vasectomy; hormonal (oral, subdermal implants, injectables, ring, patch); intrauterine device (progesterone or copper); barrier (condoms, spermicides, contraceptive sponge, diaphragm, cervical cap); and abstinence or not sexually active. We defined women "at risk" for an adverse fetal effect as those prescribed an ACE-I, ARB, or statin with no documentation of contraception.

\section{Analysis}

The Coordinating Center collected, compiled, and analyzed data from all participating sites. During the QI intervention, providers verified their patients' baseline contraceptive methods, and these data were substituted for the chart abstraction data when they differed. Univariate analysis was used to describe the population and its use of contraception. Using the Wilcoxon signed-rank sum test, the Coordinating Center compared data from before and after the intervention for documentation of informed consent and for being "at risk" of an adverse fetal event. Finally, these results were confirmed using a repeated measures logistic regression to adjust for patient characteristics.

\section{Results}

\section{Patient Characteristics}

There were 328 patients across 7 sites who met eligibility criteria (Figure 1). Individual sites contributed between $6 \%$ and $30 \%$ of the total sample. The patients' mean age was 38 years (Table 2), with a substantial majority $(74.7 \%)$ at the older end of the age distribution (35-44 years). Overall, 69.4\% of the women were white and $17.5 \%$ black, although there were substantial missing race/ethnicity data. Medicaid (43.0\%) and private $(32.3 \%)$ were the most common types of health insurance. Patients frequently had multiple visits within the 1-year time frame used for collecting baseline data (median visits, 4), and most saw more than 1 provider (median number of providers, 2).
Figure 1. Study sample flow diagram. QI, quality improvement.

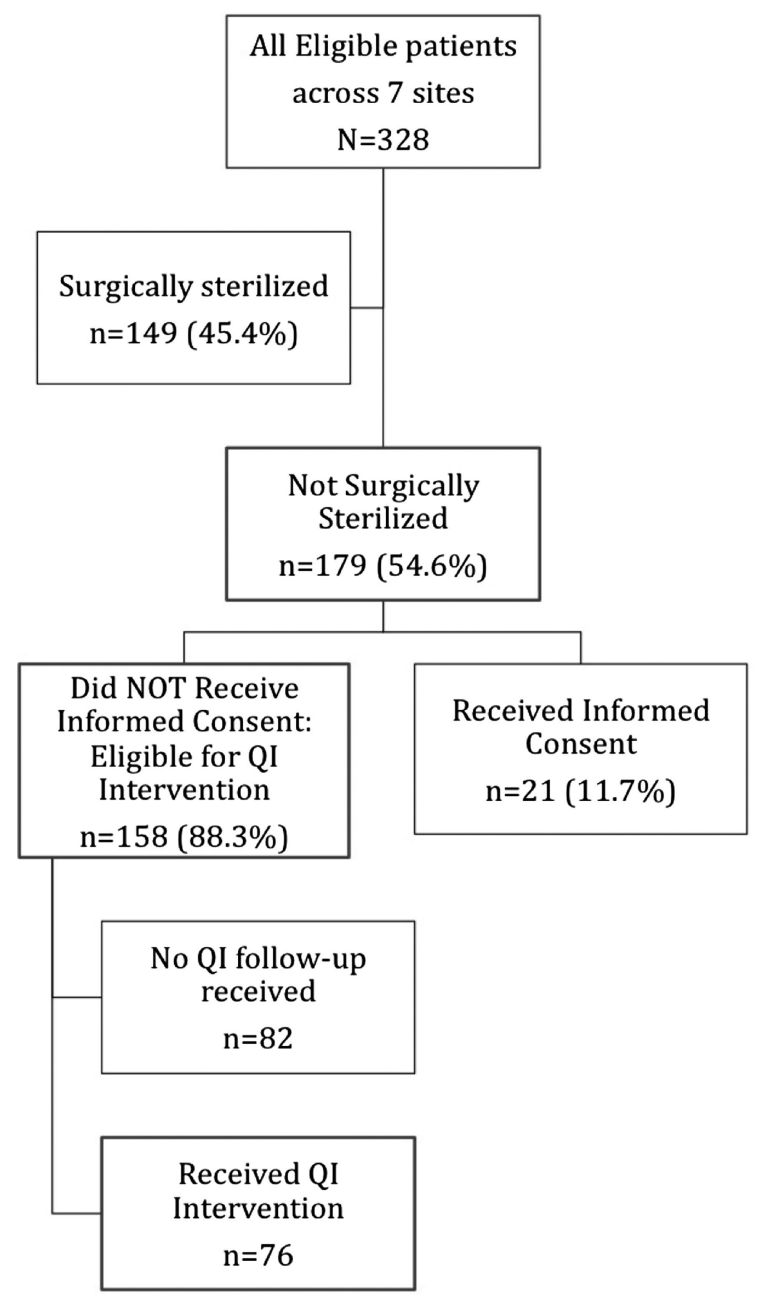

\section{ACE-I, ARB, and Statin Use}

Nearly two thirds of the study patients had each of the 3 diagnoses of interest: $63.4 \%$ had hypertension; $56.7 \%$ had hypercholesterolemia; $56.7 \%$ had diabetes (Table 2). Just more than half $(54.9 \%)$ of women were taking a statin medication and $64.3 \%$ were taking an ACE-I. Only 6.4\% were taking an ARB. Three quarters of patients (74.7\%) were taking one of these medications, and $25.0 \%$ were taking 2 of the medications.

\section{Identification of Patients Eligible for the QI Intervention}

Of the women in the study population, 45.4\% (149 of 328) were surgically sterilized (Figure 1). Of the remainder who were theoretically able to bear children, only $11.7 \%$ (21 of 179) had documentation of informed consent about the risks of the study's 
Table 2. Characteristics of the Study Population

\begin{tabular}{|c|c|}
\hline \multicolumn{2}{|l|}{ Characteristic } \\
\hline Mean age, years $(\mathrm{n}=328)$ & 38.1 \\
\hline \multicolumn{2}{|l|}{ Age, years $(n=328)$} \\
\hline $18-24$ & 2.1 \\
\hline $25-34$ & 23.2 \\
\hline $35-44$ & 74.7 \\
\hline \multicolumn{2}{|l|}{ Race/ethnicity $(\mathrm{n}=229)$} \\
\hline White & 69.4 \\
\hline Black & 17.5 \\
\hline Asian & 3.1 \\
\hline Hispanic & 7.4 \\
\hline American Indian/Alaska Native & 1.3 \\
\hline Other & 1.8 \\
\hline \multicolumn{2}{|l|}{ Insurance $(\mathrm{n}=300)$} \\
\hline Medicare & 10.0 \\
\hline Medicaid & 43.0 \\
\hline Private & 32.3 \\
\hline None & 7.0 \\
\hline Other & 7.7 \\
\hline \multicolumn{2}{|l|}{ Marital status $(\mathrm{n}=291)$} \\
\hline Married/partnered & 49.1 \\
\hline Divorced/separated & 14.1 \\
\hline Single & 36.8 \\
\hline $\begin{array}{l}\text { Evidence that patient is non-English speaking } \\
\qquad(\mathrm{n}=304)\end{array}$ & 4.9 \\
\hline \multicolumn{2}{|l|}{ Conditions $(\mathrm{n}=328)$} \\
\hline Hypertension & 63.4 \\
\hline Hypercholesterolemia & 56.7 \\
\hline Diabetes & 56.7 \\
\hline 1 condition & 45.1 \\
\hline 2 conditions & 32.9 \\
\hline 3 conditions & 22.0 \\
\hline \multicolumn{2}{|l|}{ Medications $(\mathrm{n}=328)$} \\
\hline Statin & 54.9 \\
\hline ACE-I & 64.3 \\
\hline $\mathrm{ARB}$ & 6.4 \\
\hline 1 medication & 74.7 \\
\hline 2 medications & 25.0 \\
\hline 3 medications & 0.3 \\
\hline $\begin{array}{l}\text { Median number of visits during the last year } \\
\quad(\mathrm{n}=185)\end{array}$ & 4 \\
\hline $\begin{array}{l}\text { Median number of providers seen during the } \\
\text { past year }(\mathrm{n}=186)\end{array}$ & 2 \\
\hline
\end{tabular}

Data provided as percentages unless otherwise indicated. ACE-I, angiotensin-converting enzyme inhibitor; ARB, angiotensin receptor blocker.

target medications at the time of the first chart abstraction.

Women who were not surgically sterilized and had no documentation of informed consent were considered eligible for the QI intervention $(\mathrm{n}=$
158). Of those eligible, $48.1 \%(n=76)$ received the QI intervention. The percentage of women who received the intervention varied widely by site, from $14 \%$ to $80 \%$.

There were no statistically significant differences in the demographic characteristics (age, race/ ethnicity, marital status, insurance type, evidence that patient is non-English speaking) of women who $\operatorname{did}(\mathrm{n}=76)$ and did not $(\mathrm{n}=82)$ receive the QI intervention. We conducted the remaining analyses on those 76 women who were not surgically sterilized, who had no documentation of informed consent, and who received the QI intervention.

\section{Contraceptive Use}

Before the QI intervention, 21.1\% of women (16 of 76) were using hormonal contraception; $17.1 \%$ reported partner vasectomy, $7.9 \%$ used an intrauterine device, and $25.0 \%$ reported abstinence (Table 3). Almost $25 \%$ of women had no documented contraceptive method and were therefore considered "at risk" of an adverse fetal effect.

\section{Informed Consent}

Women who received the QI intervention had significantly improved documentation of informed consent ( $0 \%$ to $87.3 \%$ of the 76 women; $P \leq .001$ ) about the adverse fetal effects of ACE-I, ARB, or statin medications.

Table 3. Contraceptive Methods Used before and after the Quality Improvement Intervention

\begin{tabular}{lcc}
\hline Types of Contraceptive & $\begin{array}{c}\text { Before } \\
\text { Intervention } \\
(\mathrm{n}=76)\end{array}$ & $\begin{array}{c}\text { After } \\
\text { Intervention } \\
(\mathrm{n}=76)\end{array}$ \\
\hline Surgical sterilization & $\mathrm{NA}^{*}$ & $1(1.3)$ \\
IUD (progesterone or copper) & $6(7.9)$ & $8(10.5)$ \\
Hormonal (non-IUD) & $16(21.1)$ & $15(19.7)$ \\
Barrier & $4(5.3)$ & $7(9.2)$ \\
Partner vasectomy & $13(17.1)$ & $10(13.2)$ \\
Abstinence/not sexually active & $19(25.0)$ & $24(31.6)$ \\
None $^{\dagger}$ & $18(23.7)$ & $11(14.5)$ \\
\hline
\end{tabular}

Data provided as $\mathrm{n}(\%)$.

*Women with previous surgical sterilization were not eligible for the quality improvement intervention because they were not at risk for pregnancy.

${ }^{\dagger}$ None: either no contraceptive method was documented or patient received only contraceptive counseling; $P=.02$.

IUD, intrauterine device. 


\section{Risk of Potential Adverse Fetal Effects}

After the QI intervention, the percent of women with no evidence of a contraceptive method dropped from $23.7 \%$ (18 of 76 ) to $14.5 \%$ (11 of 76 ) $(P=.02)$. Five of the remaining 11 women with no contraception discontinued their ACE-I, ARB, or statin or switched to a different drug class. Thus, the proportion of women considered "at risk" decreased significantly after the QI intervention, from $23.7 \%$ (18 of 76 ) before the intervention to $7.9 \%$ (6 of 76) after the intervention $(P \leq .001)$. Repeated measures logistic regression adjusting for age, insurance, marital status, number of visits, and number of providers seen confirmed a significant decrease in the odds of being "at risk" of an adverse fetal effect after the QI intervention (odds ratio, $0.20 ; 95 \%$ confidence interval, $0.06-0.66$ ).

\section{Discussion}

Documentation that women taking ACE-I, ARB, or statin medications were informed of their risks of adverse fetal effects was uncommon $(11.7 \%)$ in the study clinics at baseline. In addition, among the 76 eligible patients whose contraceptive methods were verified, roughly a quarter $(23.7 \%)$ had no contraception documented in their medical record. QI interventions, when implemented, were successful at increasing the documentation of informed consent and contraception use. After receiving the QI intervention, $87.3 \%$ of women had documentation of informed consent regarding the target medication risks. In addition, the proportion of women "at risk" for an adverse fetal effect decreased significantly, from $23.7 \%$ to $7.9 \%$. A notable concern, however, is that more than half of the women in our study did not receive the QI intervention.

All clinics participating in this study were prescribing ACE-I, ARB, and statin medications to women of childbearing age. This is consistent with the findings of several other studies documenting that this is a common practice in primary care. ${ }^{6,19}$ Schwarz et $\mathrm{al}^{16}$ found that among a general population of 78,232 female veterans, aged 18 to 45 years, who had been seen at least twice during the prior year, $14.8 \%$ were prescribed ACE-Is, 1.7\% were prescribed ARBs, and 23.0\% were prescribed statins. Martin et $\mathrm{al}^{6}$ found that $46.5 \%$ of 101 patients aged 18 to 44 years at a hypertension clinic in the United Kingdom had been prescribed
ACE-Is or ARBs by their primary care providers. Among the women of childbearing age in our study who were prescribed 1 or more of the 3 target medications, ACE-Is were the most frequently prescribed $(64.3 \%)$, followed by statins $(55.9 \%)$ and ARBs (2.4\%). Morrical-Kline et $\mathrm{al}^{19}$ defined a similar study population at a primary care center in Indianapolis, Indiana, and found the same relative prescription frequency: ACE-Is, 64.5\%; statins, $44.0 \%$; and ARBs, $14.5 \%$. Differences in regional prescribing practices may explain the modest differences in drug use between these studies. ${ }^{16}$

At baseline, women's charts infrequently documented informed consent related to the potential adverse fetal effects of ACE-Is, ARBs, or statins. This may represent a problem with documentation rather than lack of informed consent. Alternately, providers may assume that the medication package inserts or information sheets discussing adverse medication effects frequently provided by dispensing pharmacists will serve this purpose. However, several surveys have found that physicians believe they should be providing information about contraception and medications that may cause adverse fetal effects, ${ }^{18,21}$ and women want to receive information about such adverse effects. ${ }^{22}$

The finding that not all women taking ACE-I, $\mathrm{ARB}$, or statin medications had evidence of contraception is concerning but not surprising. Several studies have identified barriers to counseling women about contraception and medication-related risk of birth defects, ${ }^{21-24}$ including lack of relevant information sources, time, reimbursement, ${ }^{18,21,23}$ and providers' lack of knowledge about medications with potential adverse fetal effects. ${ }^{18,23}$ These factors have been shown to contribute to low rates of counseling and subsequent provision of contraception to women taking category D or X medications. ${ }^{16,17,25}$ Providing contraception to women using ACE-Is, ARBs, or statins is an important step toward minimizing potential risk, but it does not ensure safety. Steinkellner et $\mathrm{al},{ }^{25}$ for example, found refill patterns for oral contraceptives that suggest high rates of nonadherence among women taking pregnancy category $\mathrm{X}$ drugs. Barriers to documentation of contraception in some EMR systems may also have influenced our study findings. Different EMR systems may be more or less intuitive, complete, and useful for documenting contraceptive use. 
Several factors may have contributed to the incomplete implementation of QI interventions across the study sites. First, we depended on individual clinics' processes for the QI intervention content and implementation. The clinics varied widely in the institutional resources and personnel dedicated to QI efforts. Second, QI implementation was dependent on providers contacting their own patients. We heard anecdotal reports that some providers felt that because adverse fetal effects from ACE-Is, ARBs, or statins are rare events and these women's chronic diseases can have significant negative sequelae, the topic of the QI intervention was not compelling to them. Third, it may have been uncomfortable for providers to initiate a discussion about potential adverse fetal effects of medications that previously had been prescribed to these women. Finally, family medicine resident physicians prescribed the medications for many of the women in this study. Residents have unique challenges in delivering individual providerbased QI interventions, including interrupted continuity and a lack of consistent clinic schedules. ${ }^{26}$ Also, residents may be less comfortable delivering messages to patients about errors or quality improvement ${ }^{27}$ and may feel poorly equipped to discuss the relative benefits and risks of the target medications and contraception. ${ }^{18}$

\section{Limitations}

This study is limited first by its before/after study design without a control group; the change in the proportion of women at risk could have been due to temporal changes unrelated to the QI intervention. However, the time interval between the first and second chart reviews was short-roughly 2 months-making significant temporal changes unlikely. Employing a study design that randomized clinics to a control group would have been challenging because all clinics were eager to participate in the QI component of this highly participatory practice-based research. Second, a sizeable proportion of eligible women did not receive the QI intervention. It is possible that the 2-month interval for completion of the QI intervention was too short, especially in residency training settings, where the majority of providers practice only part time. However, the Coordinating Center recommended that eligible patients be contacted for discussion of their medications and contraceptive methods within 1 week of identifying them. Thus, the QI intervention should have taken place well within the 2-month interval. Third, we do not know whether the women who did not receive the QI intervention were concentrated among certain providers, which could decrease the generalizability of our study findings. In addition, our study population's baseline rate of tubal ligation and hysterectomy was high compared with published rates for the general population, possibly limiting the generalizability of the findings of our study. ${ }^{28,29}$ Fourth, there was site-based variation in how the research and QI intervention were conducted. The project used individuals on site, rather than a single studywide abstractor, to collect data; thus there were likely differences in abstraction at each site. To mitigate variation, the Coordinating Center provided study procedure guidance and a recommended QI intervention strategy. The conduct of this study in 7 real-world clinics is also its strength, despite their inherent variations. Last, although we limited our analysis to ACE-Is, ARBs, and statins, there are many other medications with the potential to cause adverse fetal effects if used during pregnancy. Additional research is needed to determine if our findings apply to these other medications.

\section{Conclusions}

At baseline, documentation of informed consent was infrequent and contraception was not uniform in this population of women of childbearing age receiving ACE-I, ARB, or statin medications. Introduction of a QI intervention improved care across multiple clinics, but more work is needed on how to implement QI interventions consistently in clinics. The EMR offers promise as a tool that could remind physicians to inform women of the risks of such medications and to ensure appropriate contraception, if indicated. Future research should evaluate the role of these EMR systems and the role of team-based systems of care in addressing the widespread problem of prescribing medications with potential adverse fetal effects to women who are not using contraception.

\section{References}

1. Egan BM, Zhao Y, Axon RN. US trends in prevalence, awareness, treatment, and control of hypertension, 1988-2008. JAMA 2010;303:2043-50.

2. Hyre AD, Muntner P, Menke A, Raggi P, He J. Trends in ATP-III-defined high blood cholesterol 
prevalence, awareness, treatment and control among U.S. adults. Ann Epidemiol 2007;17:548-55.

3. Mann D, Reynolds K, Smith D, Muntner P. Trends in statin use and low-density lipoprotein cholesterol levels among US adults: impact of the 2001 National Cholesterol Education Program guidelines. Ann Pharmacother 2008;42:1208-15.

4. Centers for Disease Control and Prevention. Diabetes data \& trends. Number (in millions) of civilian, non-institutionalized persons with diagnosed diabetes, United States, 1980-2009. Available from: http://www.cdc.gov/diabetes/statistics/prev/national/ figpersons.htm. Accessed August 18, 2011.

5. Chobanian AV, Bakris GL, Black HR, et al. The Seventh Report of the Joint National Committee on Prevention, Detection, Evaluation, and Treatment of High Blood Pressure: the JNC 7 report. JAMA 2003;289:2560-72.

6. Martin U, Foreman MA, Travis JC, Casson D, Coleman JJ. Use of ACE inhibitors and ARBs in hypertensive women of childbearing age. J Clin Pharm Ther 2008;33:507-11.

7. Centers for Disease Control and Prevention (CDC). Vital signs: prevalence, treatment, and control of high levels of low-density lipoprotein cholesterolUnited States, 1999-2002 and 2005-2008. MMWR Morb Mortal Wkly Rep 2011;60:109-14.

8. Centers for Disease Control and Prevention (CDC). Vital signs: prevalence, treatment, and control of hypertension-United States, 1999-2002 and 20052008. MMWR Morb Mortal Wkly Rep 2011;60: 103-8.

9. Cooper WO, Hernandez-Diaz S, Arbogast PG, et al. Major congenital malformations after first-trimester exposure to ACE inhibitors. N Engl J Med 2006; 354:2443-51.

10. Quan A. Fetopathy associated with exposure to angiotensin converting enzyme inhibitors and angiotensin receptor antagonists. Early Hum Dev 2006; 82:23-8.

11. Edison RJ, Muenke M. Mechanistic and epidemiologic considerations in the evaluation of adverse birth outcomes following gestational exposure to statins. Am J Med Genet A 2004;131:287-98.

12. Edison RJ, Muenke M. Central nervous system and limb anomalies in case reports of first-trimester statin exposure. N Engl J Med 2004;350:1579-82.

13. Kazmin A, Garcia-Bournissen F, Koren G. Risks of statin use during pregnancy: a systematic review. J Obstet Gynaecol Can 2007;29:906-8.

14. Bowen ME, Ray WA, Arbogast PG, Ding H, Cooper WO. Increasing exposure to angiotensin-converting enzyme inhibitors in pregnancy. Am J Obstet Gynecol 2008;198:291.e1-5.

15. Lee C, Force RW, Pugmire BA, Owens CT. Use of ACE-inhibitors, angiotensin II receptor blockers, and statins in women of childbearing age. Pharmacotherapy 2008;28:72e.

16. Schwarz EB, Longo LS, Zhao X, Stone RA, Cunningham F, Good CB. Provision of potentially teratogenic medications to female veterans of childbearing age. Med Care 2010;48:834-42.

17. Schwarz EB, Postlethwaite DA, Hung YY, Armstrong MA. Documentation of contraception and pregnancy when prescribing potentially teratogenic medications for reproductive-age women. Ann Intern Med 2007;147:370-6.

18. Eisenberg DL, Stika C, Desai A, Baker D, Yost KJ. Providing contraception for women taking potentially teratogenic medications: a survey of internal medicine physicians' knowledge, attitudes and barriers. J Gen Intern Med 2010;25:291-7.

19. Morrical-Kline KA, Walton AM, Guildenbecher TM. Teratogen use in women of childbearing potential: an intervention study. J Am Board Fam Med 2011;24:262-71.

20. Schwarz EB, Maselli J, Norton M, Gonzales R. Prescription of teratogenic medications in United States ambulatory practices. Am J Med 2005;118:1240-9.

21. Schwarz EB, Santucci A, Borrero S, Akers AY, Nikolajski C, Gold MA. Perspectives of primary care clinicians on teratogenic risk counseling. Birth Defects Res A Clin Mol Teratol 2009;85:858-63.

22. Santucci AK, Gold MA, Akers AY, Borrero S, Schwarz EB. Women's perspectives on counseling about risks for medication-induced birth defects. Birth Defects Res A Clin Mol Teratol 2009;88:64-9.

23. Lohr PA, Schwarz EB, Gladstein JE, Nelson AL. Provision of contraceptive counseling by internal medicine residents. J Womens Health (Larchmt) 2009; 18:127-31.

24. Weisman CS, Maccannon DS, Henderson JT, Shortridge E, Orso CL. Contraceptive counseling in managed care: preventing unintended pregnancy in adults. Womens Health Issues 2002;12:79-95.

25. Steinkellner A, Chen W, Denison SE. Adherence to oral contraception in women on Category X medications. Am J Med 2010;123:929-34 e1.

26. Darden PM, Ector W, Moran C, Quattlebaum TG. Comparison of continuity in a resident versus private practice. Pediatrics 2001;108:1263-8.

27. Gallagher TH, Waterman AD, Ebers AG, Fraser VJ, Levinson W. Patients' and physicians' attitudes regarding the disclosure of medical errors. JAMA 2003;289:1001-7.

28. Mosher WD, Jones J. Use of contraception in the United States: 1982-2008. Vital Health Stat 23. 2010;(29):1-44.

29. Schwarz EB, Postlethwaite D, Hung YY, Lantzman E, Armstrong MA, Horberg MA. Provision of contraceptive services to women with diabetes mellitus. J Gen Intern Med 2012;27:196-201. 